\title{
Preparation of Sulfhydryl Functionalized Mesoporous Silica Particles and Application in Adsorption of $\mathbf{C d}^{2+}$
}

\author{
Hong Yu*, Jiaming Zhang, Shihan Mao, Xiao Wei \\ Key Laboratory of MEMS Ministry of Education, Southeast University, Nanjing, China \\ Email: ^h_yu@seu.edu.cn
}

How to cite this paper: Yu, H., Zhang, J.M., Mao, S.H. and Wei, X. (2021) Preparation of Sulfhydryl Functionalized Mesoporous Silica Particles and Application in Adsorption of $\mathrm{Cd}^{2+}$. Advances in Materials Physics and Chemistry, 11, 202-211.

https://doi.org/10.4236/ampc.2021.1111018

Received: October 1, 2021

Accepted: November 22, 2021

Published: November 25, 2021

Copyright $\odot 2021$ by author(s) and Scientific Research Publishing Inc. This work is licensed under the Creative Commons Attribution International License (CC BY 4.0).

http://creativecommons.org/licenses/by/4.0/

\begin{abstract}
An improved soft template method to prepare sulfhydryl functionalized mesoporous silica nanoparticles is proposed. It is shown that the prepared nanoparticles maintain a relatively uniform spherical structure with a particle size range of $20-30 \mathrm{~nm}$ and a large specific surface area of about $926 \mathrm{~m}^{2} / \mathrm{g}$. The sample is used to absorb heavy metal Cadmium ions $\left(\mathrm{Cd}^{2+}\right)$ in water. The experimental results show that the sulfhydryl functionalized mesoporous silica is sensitive to Cadmium ions and has good selectivity. The detection limit can be estimated to be as low as $1.35 \mu \mathrm{g} / \mathrm{L}$.
\end{abstract}

\section{Keywords}

Mesoporous Silica Nanoparticles, Functionalized, Cadmium Ions

\section{Introduction}

Mesoporous silica nanoparticles (MSNPs), possession of pore diameter in the range of $2-50 \mathrm{~nm}$, have unique properties, such as easily tunable particle size, high stability and rigid framework, easily tunable and uniform pore size, high pore volume and greater surface area, bifunctional surfaces, and simple fabrication. MSNPs have attracted considerable attention because of their potential applications in drug release systems, catalysis, chromatography, and adsorption/ desorption of heavy metal ions or dyes in waste water [1] [2] [3] [4]. The features of greater surface area and bifunctional surfaces permit the functionalization of surfaces of MSNPs with different molecules or functional groups to enhance the selectivity in the application of adsorption/desorption of heavy metal ions [5]. The functionalization can be achieved by the grafting method (postsynthesis modification) or the co-condensation process (one-pot synthesis) [6] 
[7] [8] [9]. Yeung [10] prepared the ordered mesoporous silica adsorbents by grafting amino- and carboxylic-containing functional groups to remove acid blue 25 and Methylene blue dyes from water. Murakami [11] synthesized aminofunctionalized mesoporous silica coated with the temperature-responsive copolymer, poly(N-isopropyl acrylamide-co-acrylamide) (P(NIPAM-co-Am)), and investigated the temperature dependence of the adsorption/desorption of the methyl orange (MO) anions. Chen and He [12] synthesized functional chiral porous silica nanorods by a one-step process. They showed that the chiral nanorods could be used as a highly selective adsorbent for $\mathrm{Hg}^{2+}$ ions in the wastewater. $\mathrm{Li}$ and Mao [13] synthesized monodispersed mesoporous silica particles and functionalized the MSNPs by co-condensation of tetraethyloxane silane and mercaptopropylsilane. The products showed a good performance in the removal of $\mathrm{Au}^{3+}$ and $\mathrm{Hg}^{2+}$.

So far, only rare reports have been given to show the adsorption of heavy metal ion $\mathrm{Cd}^{2+}$ by mesoporous silica [14]. As we all know, $\mathrm{Cd}^{2+}$ is a highly toxic heavy metal ion, which is bioaccumulative, nondegradable, carcinogenic, and can cause danger to humans even at very low concentrations [15]. $\mathrm{Cd}^{2+}$ can be commonly found in industrial wastewater, including mining, smelting, electroplating, nuclear, and other industries [16]. According to the World Health Organization, the maximum permissible level of cadmium in drinking water is 0.005 $\mathrm{mg} / \mathrm{L}$ [17]. If ingested beyond the limit, it would lead to carcinogenesis, renal dysfunction, and lung damage in humans [18]. Considering the terrible harm of $\mathrm{Cd}^{2+}$ to human health, the detection and removal of $\mathrm{Cd}^{2+}$ in industrial wastewater are essential.

In this paper, low-cost and high-stability sulfhydryl functionalized mesoporous silica nanoparticles were successfully prepared by an improved soft template method. The functionalization results of mesoporous silica and the ability to absorb heavy metal ions were studied. The test results show that the sulfhydryl functionalized mesoporous silica particles have good selectivity and a low detection limit for Cadmium ions $\mathrm{Cd}^{2+}$.

\section{Materials and Methods}

\subsection{Preparation of Materials}

Mesoporous silica nanoparticles with thiol groups were prepared by a surfactant-assembly sol-gel process in a solution containing deionized water (DI), tetraethylethylenediamine (THEEDA), n-cetyltrimethylammonium bromide (CTAB), tetraethylorthosilicate (TEOS), and (3-Mercaptopropyl) trimethoxysilane (MPTMS). The typical synthetic procedure is as follows: $\mathrm{CTAB}$ was dissolved in a mixed solution containing deionized water and THEEDA at $60^{\circ} \mathrm{C}$, and a mixture of TEOS and MPTMS was immediately added under vigorous stirring. The molar ratio of the reaction mixture was 1TEOS:0.025THEEDA:0.03MPTMS: 0.1CTAB: 206DI. After being stirred at $60^{\circ} \mathrm{C}$ for 2.5 hours, the solution was allowed to stand at room temperature for 4 hours. The surfactant templates were removed 
by extraction in acidic ethanol rather than by calcination. Then samples were collected by centrifugation, washed, and redispersed with deionized water and ethanol several times. After being ground carefully, the sample was finally weighed and dissolved in ethanol for ultrasonic dispersion for 60 minutes [19]. The sample was named MSS- $\mathrm{x}$ (MSS stands for mesoporous silica spheres, $\mathrm{x}$ is the amount of MPTMS).

\subsection{Characterization}

$\mathrm{X}$-ray Diffractometer was used to get the XRD patterns of the prepared sulfhydryl functionalized mesoporous silica nanoparticles. The specific surface area was calculated by Brunauer-Emmett-Teller (BET) analysis using the automatic specific surface area and pore analyzer. The pore size distribution and pore volume were obtained by the Barrett-Joyner-Halenda (BJH) method. Scanning electron microscope (SEM) images were taken by Gemini SEM 500 with an ultrahigh-resolution, and transmission electron microscope (TEM) images were obtained using a transmission electron microscopy TECNAI G2 20 TEM.

\subsection{Adsorption of Heavy Metal Ions Experiments}

Prepared MSS-x nanoparticles were transferred onto a silicon wafer with a thin gold film on the top surface. Then the wafer with a sample was put into $\mathrm{CdCl}_{2}$ solution for 2 hours at different temperatures. The mass proportion of $\mathrm{Cd}^{2+}$ adsorbed by the sample of MSNPs was analyzed using an Energy Disperse Spectroscopy (EDS). Prepare $\mathrm{Cd}^{2+}$ ion solutions with different concentrations of $\mathrm{CdCl}_{2}$, and repeat the adsorption test. Repeat the adsorption experiments at $60^{\circ} \mathrm{C}$

Prepare the mixed solution saturated with $\mathrm{Cd}^{2+}, \mathrm{Cr}^{2+}$, and $\mathrm{Pb}^{2+}$ ions, repeat the adsorption test to investigate the selectivity of MSNPs.

\section{Results and Discussion}

\subsection{Nanoparticle Size, Surface Area, and Pore Size}

Figure 1 shows the BET curves of the prepared sulfhydryl functionalized mesoporous silica nanoparticles. The samples were named MSS- $30^{\mathrm{a}}, \mathrm{MSS}-30^{\mathrm{b}}$, and MSS-60, respectively. MSS- $30^{\mathrm{b}}$ is the sample prepared by the procedure described in section 2.1 with $30 \mu \mathrm{L}$ of MPTMS, and MSS-60 was synthesized by this method but with $60 \mu \mathrm{L}$ of MPTMS. In comparison, MSS- $30^{a}$ was synthesized by the method described in reference [13] with the drug ratio of $1.0 \mathrm{SiO}_{2}: 0.06 \mathrm{CTAB}$ : 0.026THEEDA: 0.03 MPTMS: $83 \mathrm{H}_{2} \mathrm{O}$, which means that the added MPTMS is 30 $\mu \mathrm{L}, \mathrm{CTAB}$ is $0.1464 \mathrm{~g}$, and TEOS is $1.5 \mathrm{~mL}$.

Based on the BET curves above, the specific surface area, the pore volume, and the pore size of these samples were calculated and listed in Table 1.

The data in Table 1 show that all the sulfhydryl functionalized mesoporous silica samples have high specific surface areas, large pore size, and pore volume, which provide good conditions for the adsorption of heavy metal ions. Among 
Table 1. Pore structure data of sulfhydryl functionalized mesoporous silicon.

\begin{tabular}{cccc}
\hline Sample & BET surface area $\left[\mathrm{m}^{2} / \mathrm{g}\right]$ & Pore volume $\left[\mathrm{cm}^{3} / \mathrm{g}\right]$ & Pore size $[\mathrm{nm}]$ \\
\hline MSS-30 $^{\mathrm{a}}$ & 738.7954 & 1.20 & 6.91 \\
MSS-30 & 926.0099 & 2.04 & 9.25 \\
MSS-60 & 771.6563 & 1.80 & 9.35 \\
\hline
\end{tabular}

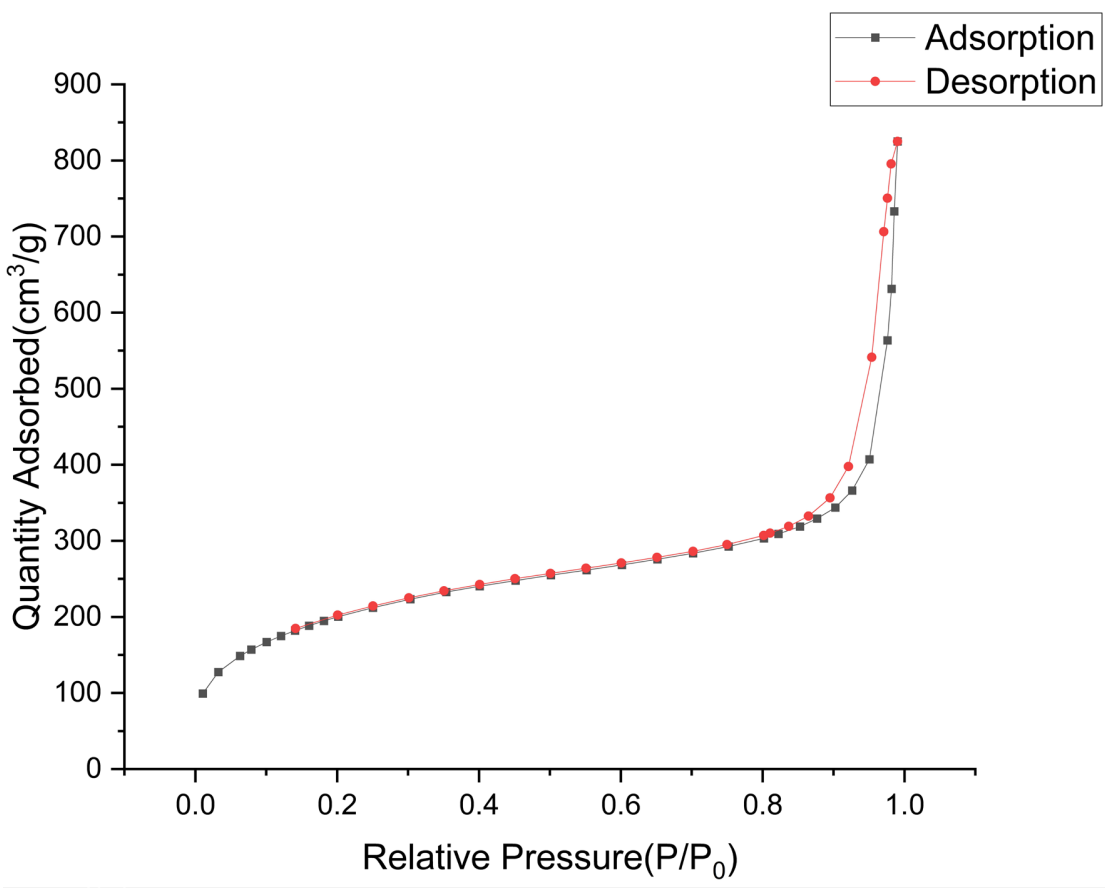

(a)

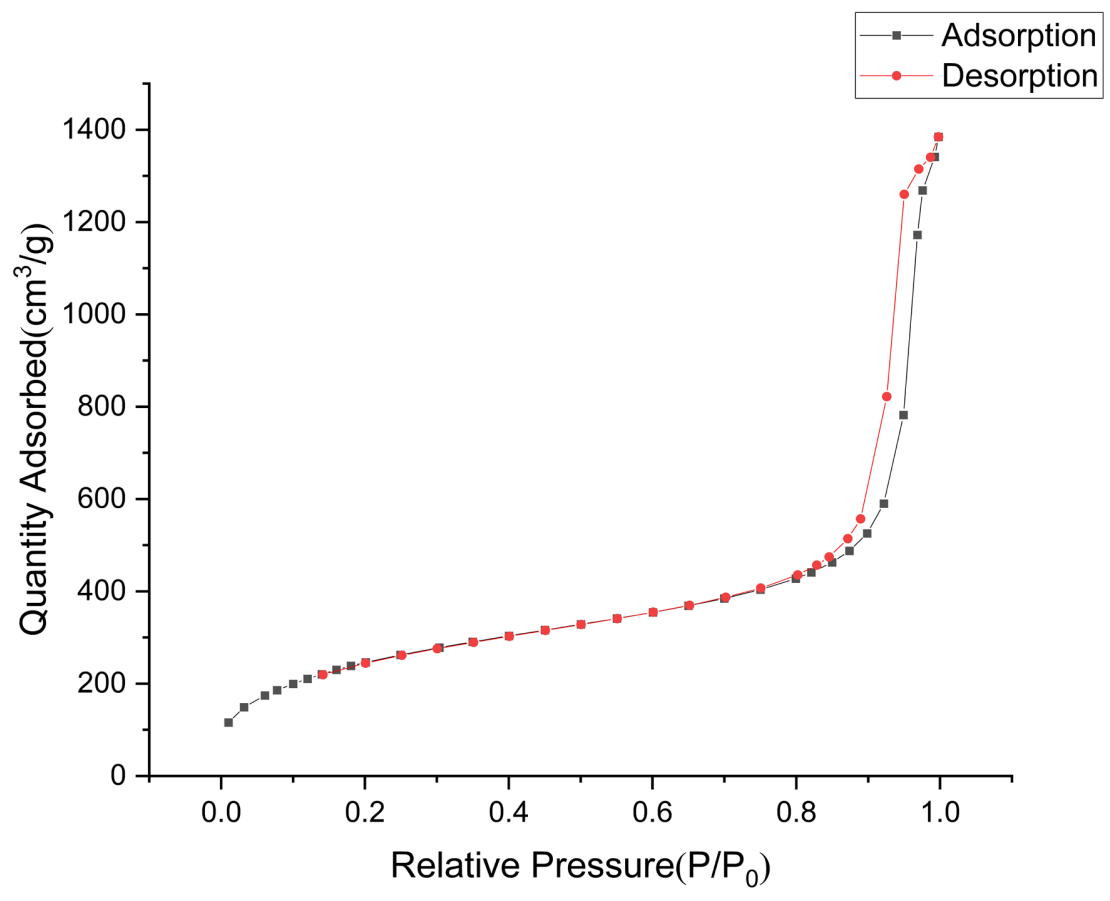

(b) 


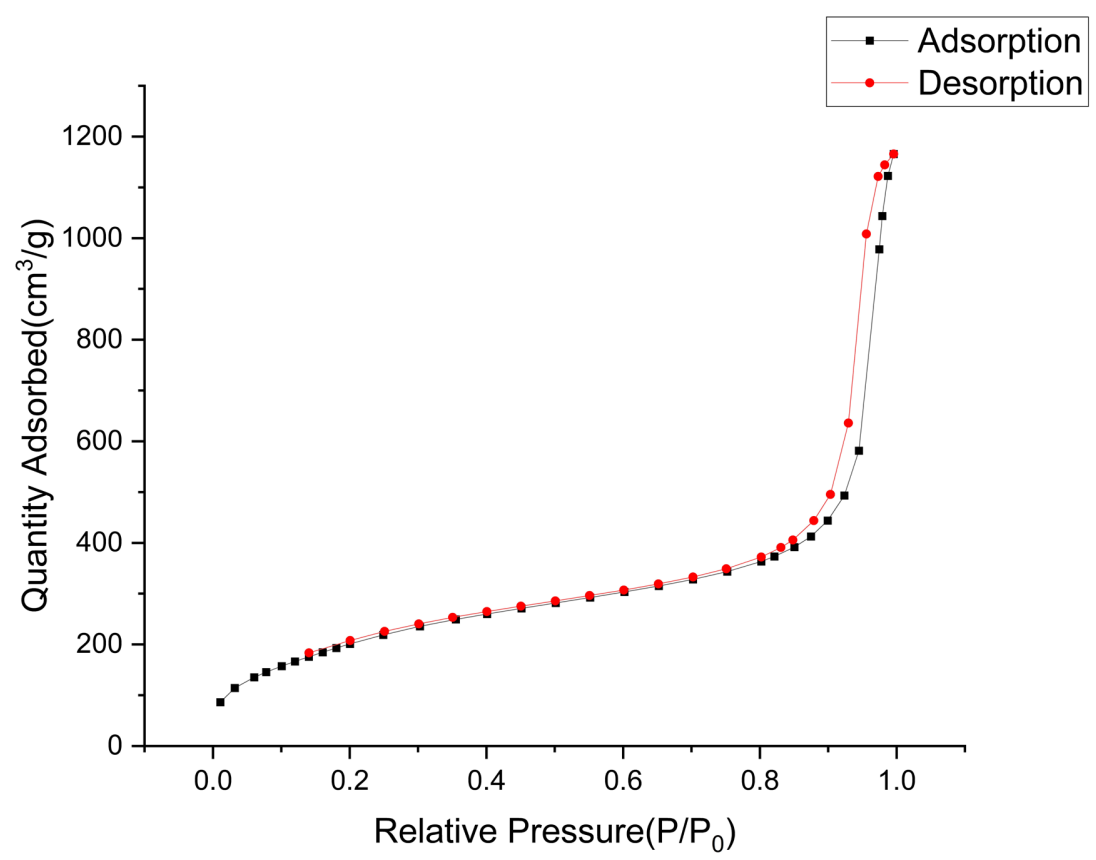

(c)

Figure 1. BET curves of (a) MSS-30 ; (b) MSS-30 ; (c) MSS-60.

them, the sample MSS $-30^{\mathrm{b}}$ has the highest surface area, pore volume, and large pore size. It was prepared by the method proposed in this paper in which the molar ratio of synthetic substances and the reaction conditions of the experiment were optimized. However, as the degree of modification increased by increasing the amount of MPTMS to $60 \mu \mathrm{L}$, the specific surface area of the mesoporous silica nanoparticles did not increase further but decreased, as displayed in Table 1 for the sample MSS-60. The reason for this might be that the grafted sulfhydryl functional groups blocked the pores too much.

An XRD pattern for the sample MSS- $30^{\mathrm{b}}$ is shown in Figure 2. In this figure, there is a diffraction peak at (100), but the diffraction peaks (110) and (200) of MCM-4 almost disappear. The disappearance of these two peaks might be due to the pores filled with the sulfhydryl groups. From the TEM image shown in Figure 3, it can be seen clearly that the sample MSS- $30^{\mathrm{b}}$ has a honeycomb-shaped pore structure. Based on Figure 2 and Figure 3, the sample MSS- $30^{\mathrm{b}}$ can be attributed to a hexagonal structure.

Figure 4 is the SEM image of the sample MSS- $30^{\mathrm{b}}$. As seen in the figure, the size of the mesoporous silica nanoparticles is from $20 \mathrm{~nm}$ to $30 \mathrm{~nm}$, and the particles show good uniformity. This uniformity makes them have a better adsorption capacity for heavy metal ions in water.

\subsection{Adsorption of Heavy Metal Ions}

Figure 5 shows the adsorption of $\mathrm{Cd}^{2+}$ by the sample MSS- $30^{\mathrm{b}}$ on a gold-silicon wafer in different concentrations of $\mathrm{CdCl}_{2}$ solutions at $30^{\circ} \mathrm{C}$ and $60^{\circ} \mathrm{C}$, respectively. The data in the figure is the average value of the EDS analysis values of 50 
microzones. It can be seen that with the increase of concentration of $\mathrm{CdCl}_{2}$ in the solution, the adsorption content of $\mathrm{Cd}^{2+}$ in the sample MSS- $30^{\mathrm{b}}$ also increases. When the temperature increases from $30^{\circ} \mathrm{C}$ to $60^{\circ} \mathrm{C}$, the adsorption rises slightly. The temperature dependence of the adsorption/desorption needs to be investigated further. The slope of the fitted line shows a strong adsorption capacity of the prepared sulfhydryl functionalized mesoporous silica nanoparticles. This figure demonstrates that MSS- $30^{\mathrm{b}}$ has an excellent adsorption capacity in $\mathrm{CdCl}_{2}$ solution with a concentration of $1.35 \mu \mathrm{g} / \mathrm{L}$.

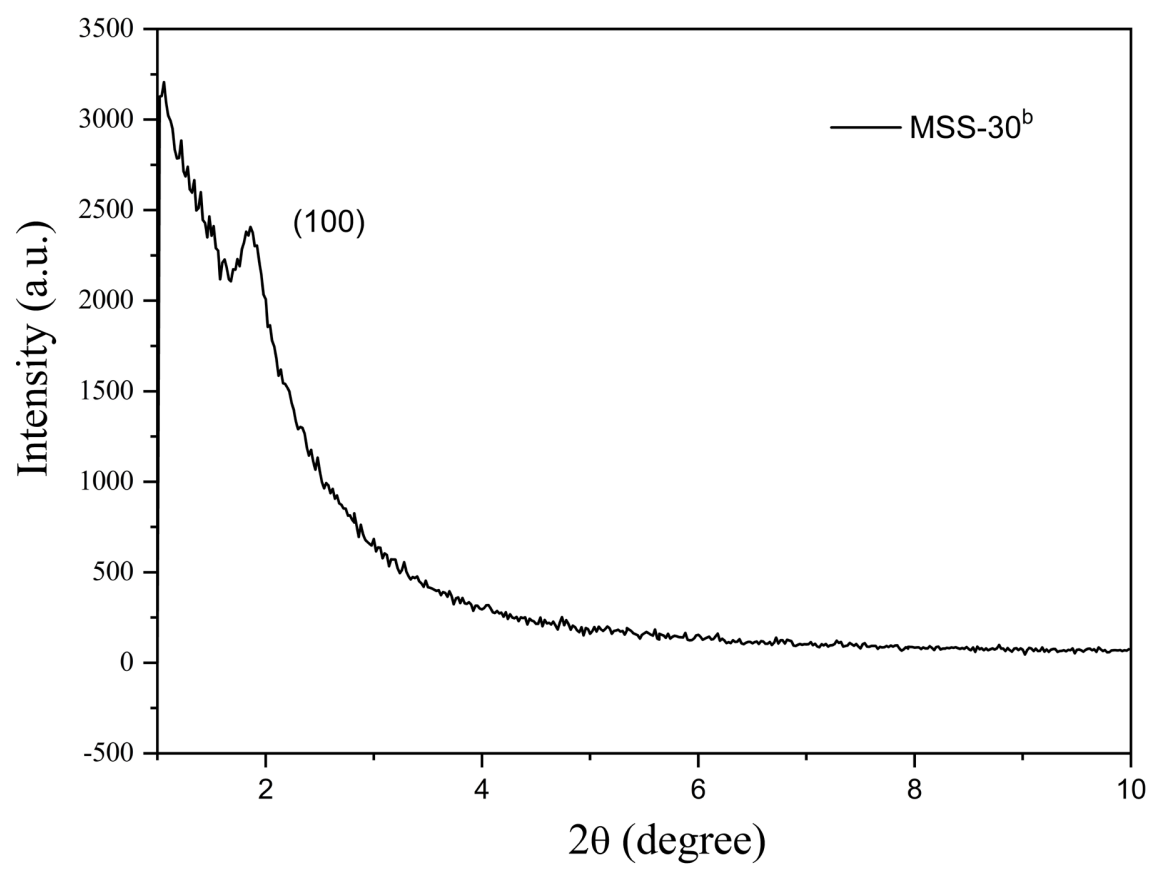

Figure 2. XRD image of sample MSS- $30^{\mathrm{b}}$.

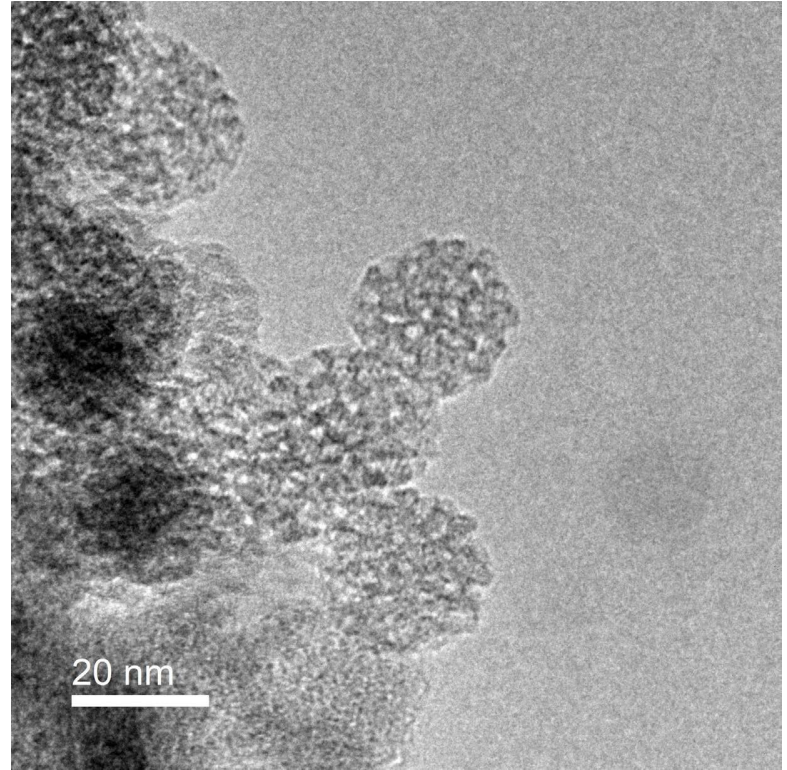

Figure 3. TEM image of sample MSS-30 ${ }^{\mathrm{b}}$. 


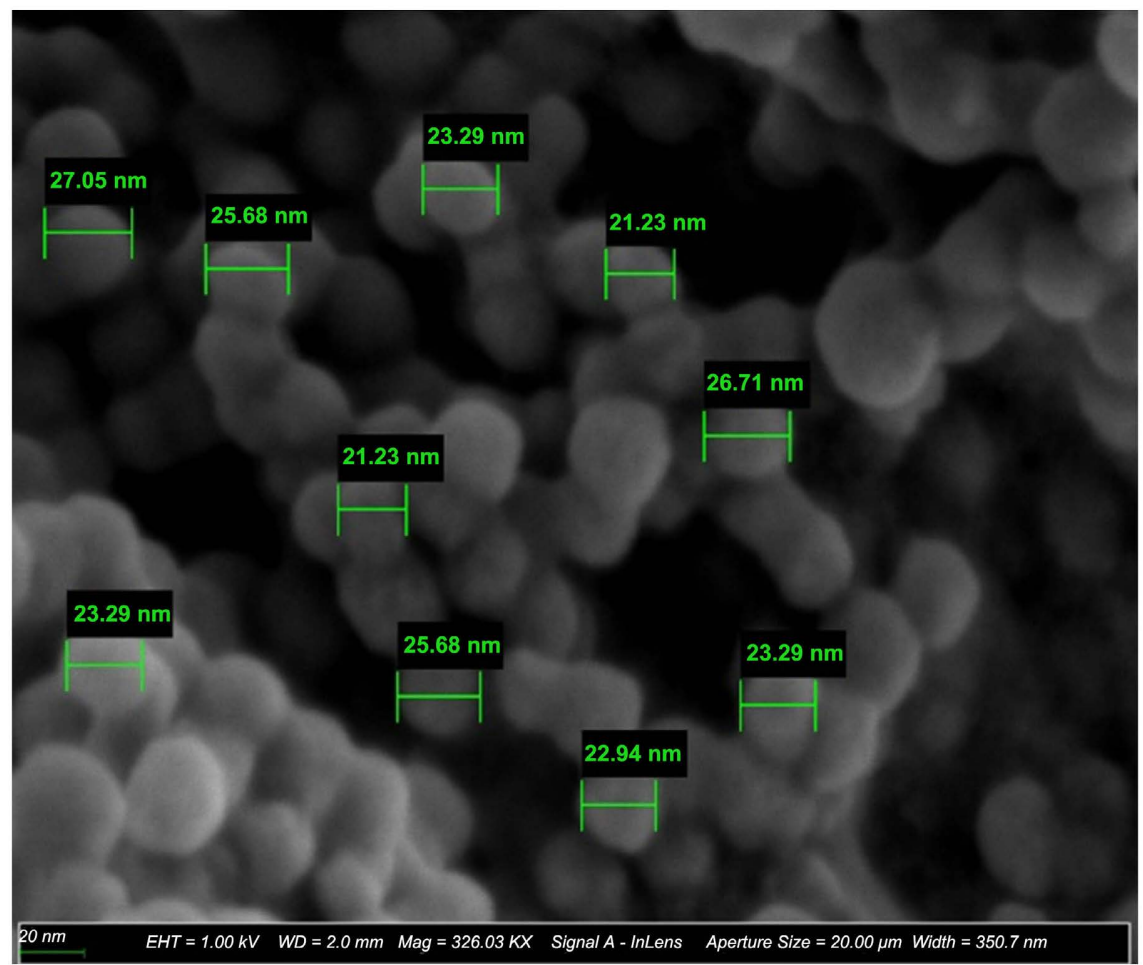

Figure 4. SEM image of sample MSS-30 .

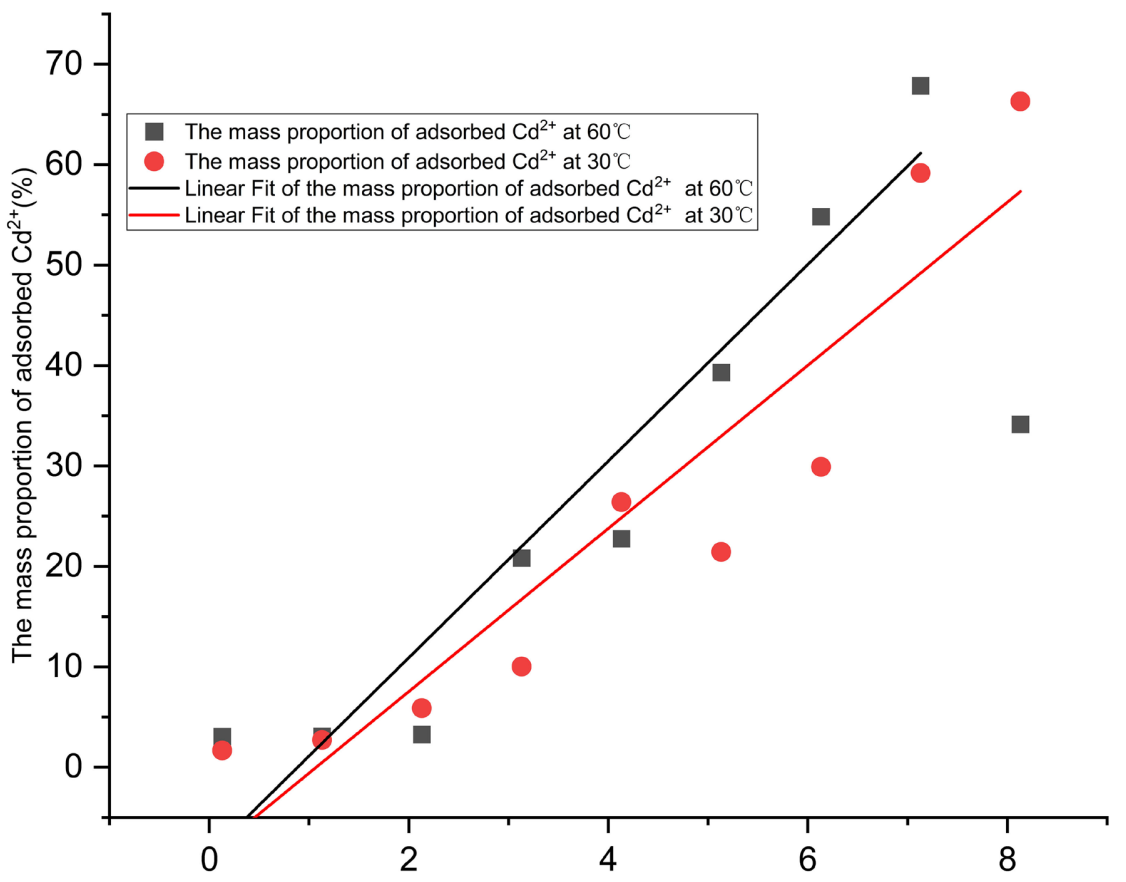

The logarithm of the concentration of $\mathrm{CdCl}_{2}$ solution $(\log (\mu \mathrm{g} / \mathrm{L}))$

Figure 5. Adsorption of $\mathrm{Cd}^{2+}$ by MSS-30 .

Figure 6 is the result of the adsorption of heavy metal ions on the surface of the MSS- $30^{\mathrm{b}}$ by EDS analysis after the sample was put into the mixed solution with $\mathrm{Pb}^{2+}, \mathrm{Cr}^{2+}$, and $\mathrm{Cd}^{2+}$ for two hours at room temperature. As the data in the 


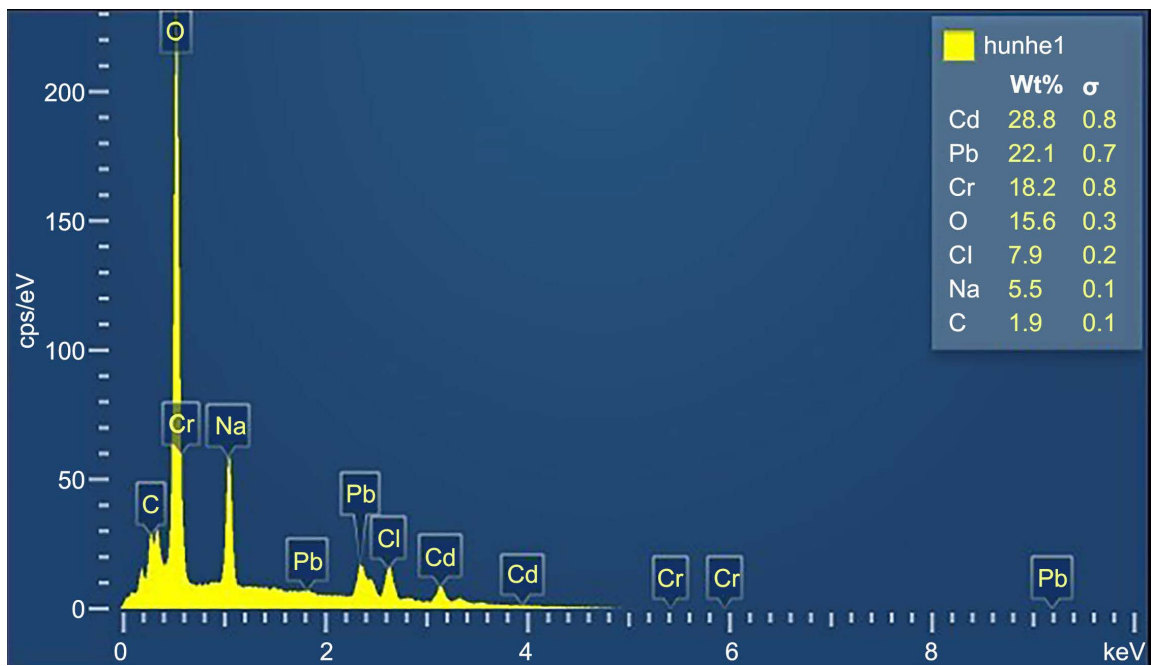

Figure 6. EDS analysis of adsorption of heavy metal ions by sample MSS-30 .

picture illustrated, the mass proportion of $\mathrm{Cd}^{2+}$ is $28.8 \%$, which is the highest value among the mass portion of $\mathrm{Pb}^{2+} 22.1 \%$ and $\mathrm{Cr}^{2+} 18.2 \%$. The experimental data reveal that the mercapto-functionalized mesoporous silicon MSS- $30^{\mathrm{b}}$ prepared in this paper has a good selectivity of $\mathrm{Cd}^{2+}$ in various heavy metal hybrid solutions due to the content of adsorbed $\mathrm{Cd}^{2+}$ being more prominent than other heavy metal ions.

\section{Conclusion}

Sulfhydryl functionalized mesoporous silica nanoparticles have been prepared successfully by an improved simple soft template method. The specific surface area of the MSNPs is as high as $926 \mathrm{~m}^{2} / \mathrm{g}$ because of the high cavities in the material's porosity. The mesoporous silica nanoparticles display high adsorption of $\mathrm{Cd}^{2+}$ by complexation between $\mathrm{Cd}^{2+}$ ions and thiol groups. The quantitative determination of $\mathrm{Cd}^{2+}$ was observed by energy dispersive spectroscopy, and the detection accuracy of $\mathrm{Cd}^{2+}$ is estimated to be $1.35 \mu \mathrm{g} / \mathrm{L}$ in the water. The experiment also showed that the prepared mercapto-functionalized mesoporous silica in this paper has a good selectivity of $\mathrm{Cd}^{2+}$ compared with other heavy metals, like $\mathrm{Pb}^{2+}$ and $\mathrm{Cr}^{2+}$. In this study, the utilization of sulfhydryl functionalized mesoporous silica nanoparticles might pave a new way to detect or remove $\mathrm{Cd}^{2+}$ in surface sewage.

\section{Acknowledgements}

This research was supported by the National Natural Science Foundation of China (Grant No. 61771137).

The authors would like to thank Professor Xiao Xie at Southeast University for his suggestion and help take the sample's TEM images.

\section{Conflicts of Interest}

The authors declare no conflicts of interest regarding the publication of this paper. 


\section{References}

[1] Pednekar, P.P., Godiyal, S.C., Jadhav, K.R. and Kadam, V.J. (2017) Chapter 23. Mesoporous Silica Nanoparticles: A Promising Multifunctional Drug Delivery System. In: Ficai, A., and Grumezescu, A.M., Eds., Nanostructures for Cancer Therapy, Elsevier, Amsterdam, 593-621. https://doi.org/10.1016/B978-0-323-46144-3.00023-4

[2] Liu, A.M., Hidajat, K. and Kawi, S. (2000) A New Class of Hybrid Mesoporous Materials with Functionalized Organic Monolayers for Selective Adsorption of Heavy Metal Ions. Chemical Communications, 13, 1145-1146.

https://doi.org/10.1039/b0026611

[3] Li, Q., Wang, Z., Fang, D.M., Qu, H.Y., Zhu, Y., Zou, H.-J., et al. (2014) Preparation, Characterization, and Highly Effective Mercury Adsorption of L-Cysteine-Functionalized Mesoporous Silica. New Journal of Chemistry, 38, 248-254. https://doi.org/10.1039/C3NJ00799E

[4] Costa, M. and Bizeto, M. (2018) Synthesis of a Highly Hydrophobic Silica Mesostructure by a Modified Co-Condensation Procedure and Evaluation of Its Drug Release Capability. Journal of Porous Materials, 25, 1603-1609. https://doi.org/10.1007/s10934-018-0574-7

[5] Cashin, V.B., Eldridge, D.S., Yu, A. and Zhao, D. (2018) Surface Functionalization and Manipulation of Mesoporous Silica Adsorbents for Improved Removal of Pollutants: A Review. Environmental Science: Water Research \& Technology, 4, 110 128. https://doi.org/10.1039/C7EW00322F

[6] Nakamura, T., Yamada, Y. and Yano, K. (2007) Direct Synthesis of Monodispersed thiol-Functionalized Nanoporous Silica Spheres and Their Application to a Colloidal Crystal Embedded with Gold Nanoparticles. Journal of Materials Chemistry, 17, 3726-3732. https://doi.org/10.1039/b705209j

[7] Möller, K., Kobler, J. and Bein, T. (2007) Colloidal Suspensions of Nanometer-Sized Mesoporous Silica. Advanced Functional Materials, 17, 605-612.

https://doi.org/10.1002/adfm.200600578

[8] Walcarius, A. (2013) Mesoporous Materials and Electrochemistry. Chemical Society Review, 42, 4098-4140. https://doi.org/10.1039/c2cs35322a

[9] Huang, Y. (2009) Functionalization of Mesoporous Silica Nanoparticles and Their Applications in Organo-, Metallic and Organometallic Catalysis, Doctoral dissertation, Iowa State University, Iowa.

[10] Ho, K., Mckay, G. and Yeung, K. (2003) Selective Adsorbents from Ordered Mesoporous Silica. Langmuir, 19, 3019-3024. https://doi.org/10.1021/la0267084

[11] Murakami, K., Sato, Y. and Inoue, Y. (2015) Synthesis of P (NIPAM-co-Am)/Mesoporous Silica Composites and Their Temperature-Responsive Anion Exchange. Journal of Materials Science and Chemical Engineering, 3, 7-15. https://doi.org/10.4236/msce.2015.37002

[12] Chen, H. and He, J. (2009) One-Step Synthesis of Functional Chiral Porous Silica Nanorods Using an Achiral Surfactant. Dalton Transactions, 33, 6651-6655. https://doi.org/10.1039/b904803k

[13] Li, X., Shi, B., Wang, Y., Li, M., Liu, Y., Gao, L. and Mao, L. (2015) Preparation of Monodispersed Mesoporous Silica Particles and Their Applications in Adsorption of $\mathrm{Au}^{3+}$ and $\mathrm{Hg}^{2+}$ after Mercapto Functionalized Treatment. Microporous and $\mathrm{Me}-$ soporous Materials, 214, 15-22. https://doi.org/10.1016/j.micromeso.2015.04.033

[14] Charoensuk, J., Thonglao, J., Wichaiyo, B., Mukdasai, K., Santaladchaiyakit, Y., Srijaranai, S., et al. (2021) A Simple and Sensitive Colorimetric Sensor for Cadmium 
(II) Detection Based on Self-Assembled Trimethyl tetradecyl Ammonium Bromide and Murexide on Colloidal Silica. Microchemical Journal, 160, Article ID: 105666. https://doi.org/10.1016/j.microc.2020.105666

[15] Robards, K. and Worsfold, P. (1991) Cadmium: Toxicology and Analysis. A Review. Analyst, 116, 549-568. https://doi.org/10.1039/an9911600549

[16] Daher, R.T. (1995) Trace Metals (Lead and Cadmium Exposure Screening). Analytical Chemistry, 67, 405-410. https://doi.org/10.1021/ac00108a022

[17] Williams, G.P., Gnanadesigan, M. and Ravikumar, S. (2012) Biosorption and BioKinetic Studies of Halobacteria Strains against $\mathrm{Ni}^{2+}, \mathrm{Al}^{3+}$, and $\mathrm{Hg}^{2+}$ Metal Ions. Bioresource Technology, 107, 526-529. https://doi.org/10.1016/j.biortech.2011.12.054

[18] Satarug, S., Garrett, S.H. and Sens, M.A. (2010) Cadmium, Environmental Exposure, and Health Outcomes. Environmental Health Perspectives, 118, 182-190. https://doi.org/10.1289/ehp.0901234

[19] Teng, Z., Zheng, G., Dou, Y., Li, W., Mou, C.-Y., Zhang, X., et al. (2012) Highly Ordered Mesoporous Silica Films with Perpendicular Mesochannels by a Simple Stöber-Solution Growth Approach. Angewandte Chemie International Edition, 51, 2173-2177. https://doi.org/10.1002/anie.201108748 